\title{
Efektivitas Kombinasi Kitosan dan Ampas Kopi sebagai Adsorben Alami dalam Menurunkan Konsentrasi Arsen Pada Limbah Cair PT PXI
}

\author{
1,2,3Universitas Pelita Bangsa, Indonesia \\ ${ }^{1}$ Institut Teknologi Bandung, Indonesia \\ Email : nisa.kimia@pelitabangsa.ac.id
}

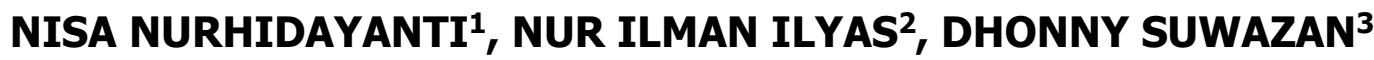

Received 17 September 2021 | Revised 17 Oktober 2021 | Accepted 21 Oktober 2021

\begin{abstract}
ABSTRAK
PXI adalah salah satu perusahaan di Kabupaten Bekasi yang bergerak di bidang jasa layanan laboratorium. Dalam menjalankan kegiatannya, PXI menghasilkan logam arsen ke lingkungan. Keberadaan arsen di dalam air limbah PXI harus segera diselesaikan agar tidak mencemari lingkungan dan membahayakan kehidupan manusia. Metode yang digunakan dalam penelitian ini adalah metode eksperimen dan deskriptif kuantitatif berdasarkan data hasil laboratorium menggunakan instrumen FT-IR, SEM EDX dan AAS. Tahapan penelitian terdiri dari sintesis, karakterisasi dan penggunaan adsorben alami untuk menurunkan logam arsen pada air limbah. Hasil penelitian menunjukkan bahwa penggunaan adsorben alami kitosan dan karbon aktif ampas kopi 1,4 gram dapat menghasilkan efisiensi penurunan logam arsen tertinggi sebesar $86,18 \%$ dengan konsentrasi akhir sebesar $0,79 \mathrm{mg} / \mathrm{L}$. Namun hasil tersebut belum memenuhi baku mutu logam arsen yang ditetapkan Peraturan Menteri Lingkungan Hidup Nomor 12 Tahun 2020. Sehingga perlu dilakukan penelitian lebih lanjut untuk meningkatkan efisiensi penurunan logam arsen.
\end{abstract}

Kata kunci: ampas kopi, arsen, adsorben alami, kitosan

\section{ABSTRACT}

PXI is one of the companies in Bekasi Regency which is engaged in laboratory services. In carrying out its activities, PXI produces arsenic metal into the environment. The presence of arsenic in PXI wastewater must be resolved immediately so as not to pollute the environment and endanger human life. The method used in this study is an experimental and quantitative descriptive method based on laboratory data using FT-IR, SEM EDX and AAS instruments. The research stages consisted of synthesis, characterization and the use of natural adsorbents to reduce arsenic metal in wastewater. The results showed that the use of chitosan natural adsorbent and 1.4 gram coffee grounds activated carbon could produce the highest arsenic metal reduction efficiency of $86.18 \%$ with a final concentration of $0.79 \mathrm{mg} / \mathrm{L}$. However, these results do not meet the quality standard for arsenic metal as stipulated by the Regulation of the Minister of the Environment Number 12 of 2020. So it is necessary to do further research to increase the efficiency of reducing metal arsenic.

Keywords: coffee grounds, arsenic, natural adsorben, chitosan 


\section{PENDAHULUAN}

Keberadaan logam berat adalah permasalahan serius yang harus segera diselesaikan, karena dampak negatif akibat keberadaan logam berat di dalam lingkungan sangat berbahaya bagi kehidupan manusia. Penghapusan logam berat beracun dari air limbah menjadi topik utama dari beberapa penelitian ilmiah dalam beberapa tahun terakhir, karena masalah toksikologi yang disebabkan terhadap sistem ekologi dan bioakumulasi logam berat dalam rantai makanan. Logam berat memiliki stabilitas yang tinggi dan mudah diikat oleh organisme melalui proses bioakumulasi logam berat dalam ekosistem. Hingga saat ini sebagian besar penelitian difokuskan pada logam berat yang lebih beracun seperti tembaga, arsen, timbal dan kadmium (Naga Babu, et al., 2018). Beberapa metode yang digunakan untuk menurunkan kadar logam berat dalam air limbah diantara-Nya dengan presipitasi kimia, adsorpsi, filtrasi membran, pertukaran ion dan koagulasi- flokulasi. Fokus penelitian dalam beberapa tahun terakhir telah memfokuskan pada penggunaan adsorben alternatif untuk menurunkan biaya penggunaan adsorben dan sifatnya yang lebih ramah lingkungan karena pengoperasiannya mudah dan efisiensinya tinggi (Kim, et al., 2014).

PT. X Indonesia (PXI) adalah salah satu perusahaan di Kabupaten Bekasi yang bergerak di bidang jasa layanan laboratorium mulai dari inspeksi, pengujian, sertifikasi dan pelatihan untuk perusahaan / industri lokal dan Multi nasional di Indonesia. PXI mengoperasikan laboratorium canggih terakreditasi ISO 17025 untuk pengujian makanan, farmasi, kosmetik dan tekstil. PXI menghasilkan limbah bahan berbahaya dan beracun yang pengolahannya diserahkan kepada pihak ketiga. Berdasarkan hasil pengujian sampel air limbah dari PXI diperoleh konsentrasi logam Arsen (As) sebesar 5,74 mg/L. Berdasarkan data tersebut disimpulkan bahwa konsentrasi logam arsen melebihi dari baku mutu yang telah ditetapkan Peraturan Menteri Lingkungan Hidup Nomor P12 Tahun 2020 pada Lampiran III tentang baku mutu air limbah pada kolam penampung air di fasilitas penyimpanan limbah B3 berupa tempat tumpukan limbah (waste pile) dan waste impoundment yaitu sebesar 0,1 mg/L (Menteri LH, 2020). Arsen (As) merupakan salah satu logam berat yang berwarna keperakan dan memiliki toksisitas tinggi (Hazimah, et al., 2018). Arsen (As) banyak ditemukan dalam air limbah industri elektronik dan gallium arsenid, industri pembuatan semikonduktor silikon karena menggunakan komposisi penyusunnya berupa arsen konsentrasi tinggi. Arsen dapat berpindah secara alami melalui reaksi kimia, aktivitas biologi, reaksi geokimia, emisi gunung berapi dan kegiatan antropologi. Keberadaan logam arsen dalam air secara alami akibat mobilitasnya menyebabkan sifat air menjadi beracun dan menjadi permasalahan di dunia pada abad 20 dan 21. Bilangan oksidasi arsen yaitu $-3,0,+3$ and +5 . Arsen di lingkungan dapat berbentuk asam $\left(\mathrm{H}_{3} \mathrm{AsO}_{3}, \mathrm{H}_{3} \mathrm{AsO}_{4}\right.$, asam metil arsenit, asam dimetil arsenit, dll) (Park, et al., 2019).Oleh karena itu perlu adanya penelitian yang dapat berkontribusi membantu PXI menyelesaikan permasalahan keberadaan logam berat dalam air limbahnya tersebut.

Penggunaan kitosan sebagai adsorben memiliki kelemahan dapat meningkatkan kekeruhan dalam air sehingga diperlukan proses lanjutan. Kombinasi kitosan dengan ampas kopi dapat meningkatkan potensi daur ulang adsorben, dapat meningkatkan stabilitas kimia dan adsorpsi kapasitas adsorben untuk meningkatkan efisiensi penurunan (Lessa, et al., 2018). Pemanfaatan kitosan dan karbon aktif dari ampas kopi sebagai adsorben dapat menurunkan kadar logam kadmium sebesar $74,54 \%$, dan nikel sebesar $73,43 \%$ (Sari, 2019), dan menurunkan logam timbal dengan efisiensi adsorpsi sebesar 92,26 \% dan konsentrasi akhir $0.774 \mathrm{mg} / \mathrm{L}$ pada waktu kontak 120 menit (Ayunda, 2019) dan menurunkan kontaminan obat pada air limbah seperti metamizole, asam asetil salisilat, acetaminophen dan kafein (Lessa, et al., 2018). Pada kesempatan ini peneliti mencoba memanfaatkan adsorben dari kitosan dan karbon aktif dari ampas kopi untuk menurunkan polutan logam berat arsen dalam 
air limbah industri PXI yang melebihi baku mutu. Penelitian ini diharapkan dapat memberikan kontribusi bagi PT PXI agar dapat membangun instalasi pengolahan air limbah (IPAL), sehingga proses pengolahannya tidak diserahkan lagi kepada pihak ketiga. Selain itu diharapkan dapat mengurangi dampak negatif pencemaran lingkungan akibat penggunaan adsorben kimia dalam pengolahan limbah cair bahan berbahaya dan beracun. Kebaruan dalam penelitian ini yaitu mengkaji efektivitas penurunan konsentrasi arsen dalam air limbah menggunakan adsorben kombinasi kitosan dan ampas kopi.

\section{METODE}

\subsection{Alat dan Bahan Penelitian}

Alat yang digunakan dalam penelitian ini terdiri dari gelas kimia, neraca analitik, kertas saring, pipet volume, corong, cawan porselen, indikator universal, oven, spatula, plat akrilik, hot plate, ayakan, tanur, desikator, karet penghisap/bulb, aluminium foil, ball mill, magnetic stirrer, vakum, spektrofotometer serapan atom (SSA/AAS), Fourier Transform-Infra Red (FT-IR) dan Scanning Electron Microscopy (SEM). Adapun kondisi operasi instrument AAS yang digunakan adalah mengikuti Tabel 1 sebagai berikut:

Tabel 1. Kondisi instrumen AAS Agilent Technologies 200 series AA pada pengukuran konsentrasi logam Arsen

\begin{tabular}{|c|l|l|l|}
\hline No & Parameter & Satuan & Nilai \\
\hline 1 & Panjang gelombang & $\mathrm{nm}$ & 193,7 \\
\hline 2 & Tipe nyala & - & Electrothermal (graphite furnace) \\
\hline 3 & Tipe lampu & - & Hollow Cathode Lamps (HCL) As \\
\hline 4 & Kecepatan aliran gas pembakar & L/menit & 0,3 \\
\hline 5 & Lebar celah & $\mathrm{nm}$ & 0,5 \\
\hline 6 & Suhu tertinggi & ${ }^{\circ} \mathrm{C}$ & 2600 \\
\hline 7 & Jenis gas & - & Argon \\
\hline
\end{tabular}

Bahan yang digunakan dalam penelitian ini terdiri dari kitosan, ampas kopi, aquades, natrium hidroksida p.a (E.Merck), asam nitrat teknis, asam asetat p.a (E.Merck), Larutan induk $\mathrm{As}^{3+}$ $100 \mu \mathrm{g} / \mathrm{L}$ dan air limbah industri PT PXI.

\subsection{Prosedur Penelitian}

\subsubsection{Pengambilan Sampel Air Limbah}

Air limbah dari PXI berasal dari satu saluran pembuangan dengan proses kontinyu. Pada PXI terdapat bak ekualisasi sehingga pengambilan sampel dilakukan pada saluran pembuangan dengan cara grab sampling sebelum memasuki perairan penerima air limbah.

Proses pengambilan sampel air limbah mengikuti diagram alir seperti disajikan dalam Gambar 1 sebagai berikut:

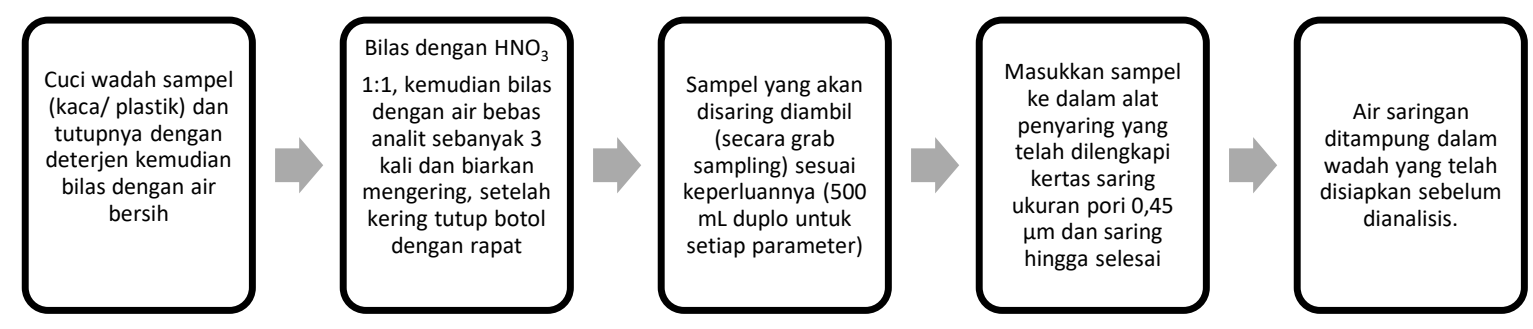

Gambar 1. Diagram Alir Proses Pengambilan Sampel Air Limbah 


\subsubsection{Uji Pendahuluan Kadar Logam Berat PT PXI}

Preparasi sampel arsen mengacu pada metode uji penentuan kadar logam dalam air dan air limbah yang telah ditetapkan oleh PXI dengan mengacu pada Metode AAS-GF: American Public Health Association 23 edition 2017 (APHA, 2017; PT.PXI, 2012). Pengujian sampel dilakukan secara duplo yaitu limbah A dan limbah B dengan data hasil pengujian awal konsentrasi Arsen dalam air limbah PT.PXI sebesar 5,74 mg/L.

\subsubsection{Pembuatan Adsorben Kitosan - Karbon Aktif Ampas Kopi}

Proses Pembuatan Adsorben Kitosan - Karbon Aktif Ampas Kopi mengikuti diagram alir seperti disajikan dalam Gambar 2 sebagai berikut:

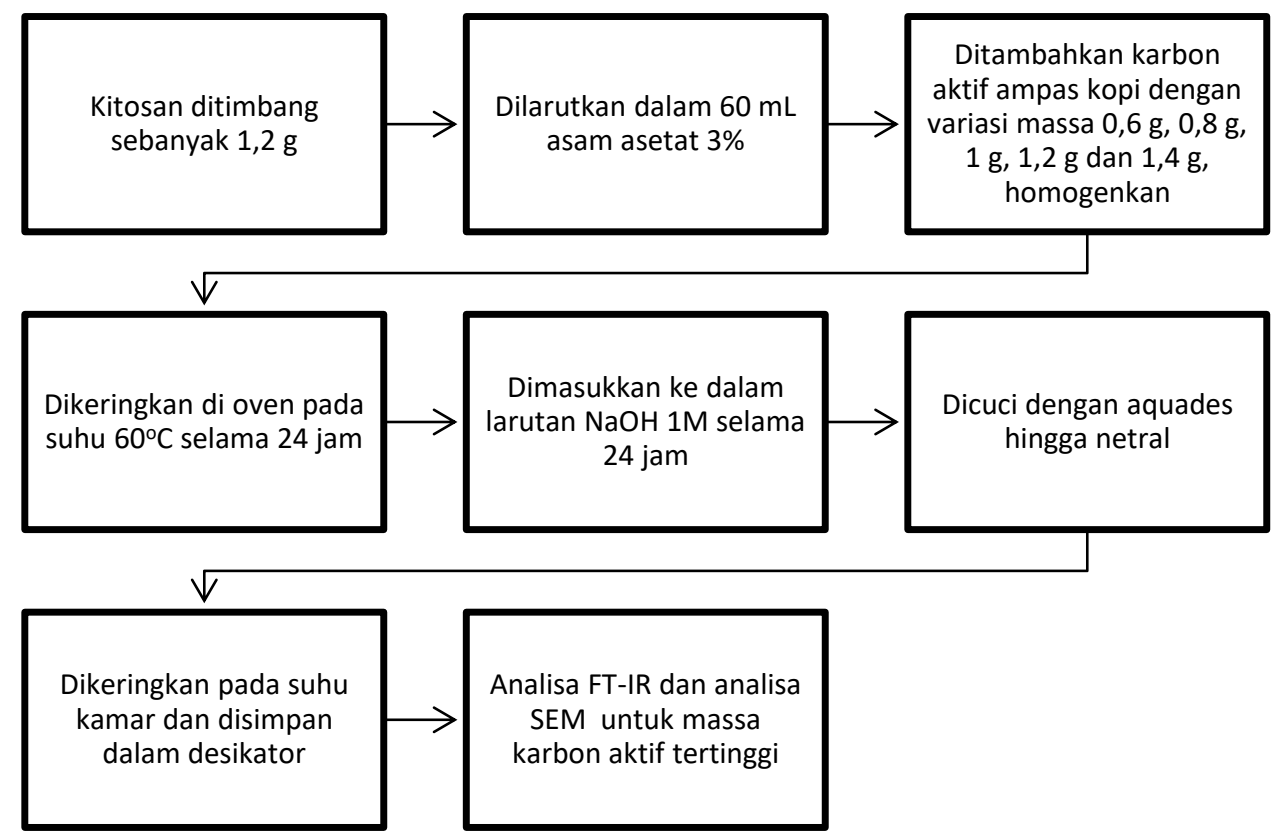

\section{Gambar 2. Diagram Alir Proses Pembuatan Adsorben Kitosan dan Karbon Aktif Ampas Kopi}

Penggunaan Adsorben Kitosan - Karbon Aktif Ampas Kopi sebagai Adsorben untuk Menurunkan Konsentrasi Logam Arsen (As) mengikuti diagram alir seperti disajikan dalam Gambar 3 sebagai berikut:

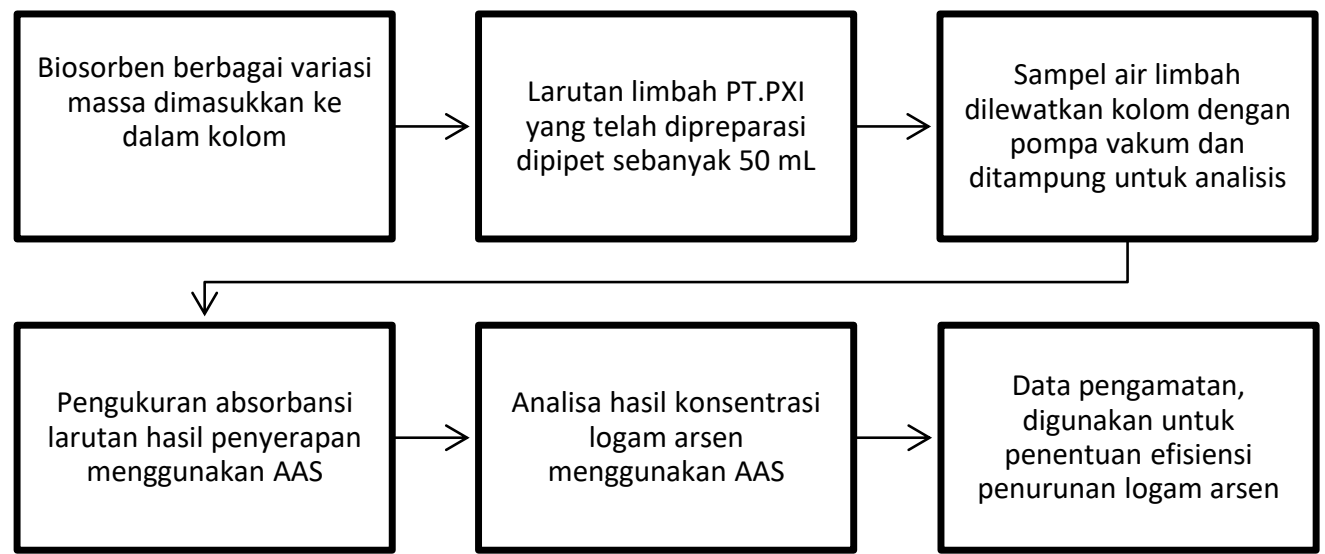

Gambar 3. Diagram Alir Proses Penggunaan Adsorben Kitosan - Karbon Aktif Ampas Kopi sebagai Adsorben untuk Menurunkan Konsentrasi Logam Arsen 


\subsection{Analisis Data}

Perhitungan Kadar arsen menggunakan Persamaan 1 sebagai berikut:

$$
\operatorname{Kadar} \operatorname{Arsen}(\mu \mathrm{g} / \mathrm{L})=\mathrm{C} \times \mathrm{Fp}
$$

Dengan pengertian $C$ adalah kadar yang didapat dari hasil pengukuran $(\mu \mathrm{g} / \mathrm{L})$ dan Fp adalah faktor pengenceran (BSN, 2005). Penentuan efektivitas penurunan konsentrasi arsen menggunakan Persamaan 2 sebagai berikut:

$$
\% \text { Efisiensi }=\frac{C i-C e}{C i} \times 100 \%
$$

Dengan pengertian \% Efisiensi adalah \% penurunan konsentrasi logam arsen; $\mathrm{Ci}$ adalah konsentrasi logam arsen awal dan Ce adalah konsentrasi logam arsen akhir (Cherdchoo et al., 2019).

\section{HASIL DAN PEMBAHASAN}

Hasil uji pendahuluan menunjukkan bahwa konsentrasi logam arsen pada air limbah industri sebesar 5,74 mg/L. Data ini menunjukkan bahwa konsentrasi logam arsen telah melebihi dari baku mutu yang telah ditetapkan Peraturan Menteri Lingkungan Hidup Nomor P12 Tahun 2020 pada Lampiran III tentang baku mutu air limbah pada kolam penampung air di fasilitas penyimpanan limbah B3 berupa tempat tumpukan limbah (waste pile) dan waste impoundment yaitu sebesar 0,1 mg/L (Menteri LH, 2020).

\subsection{Uji linearitas sampel dengan instrumen AAS}

Sebelum dilakukan analisis sampel dilakukan pengecekan linearitas kurva absorbansi terhadap instrumen yang disajikan pada Tabel 2 di bawah ini:

Tabel 2. Uji Linearitas Logam Arsen berdasarkan data absorbansi AAS

\begin{tabular}{|l|l|l|}
\hline \multicolumn{1}{|c|}{ Larutan } & \multicolumn{1}{|c|}{$\begin{array}{c}\text { Konsentrasi Arsen } \\
(\boldsymbol{\mu g / L )}\end{array}$} & \multicolumn{1}{|c|}{ Absorbansi } \\
\hline Blanko & 0 & 0,0990 \\
\hline Standar 1 & 5 & 0,0212 \\
\hline Standar 2 & 10 & 0,0306 \\
\hline Standar 3 & 25 & 0,0651 \\
\hline Standar 4 & 50 & 0,1386 \\
\hline Standar 5 & 100 & 0,2535 \\
\hline
\end{tabular}

Berdasarkan data pada Tabel 2 tersebut diperoleh kurva kalibrasi yang disajikan pada Gambar 1 sebagai berikut: 


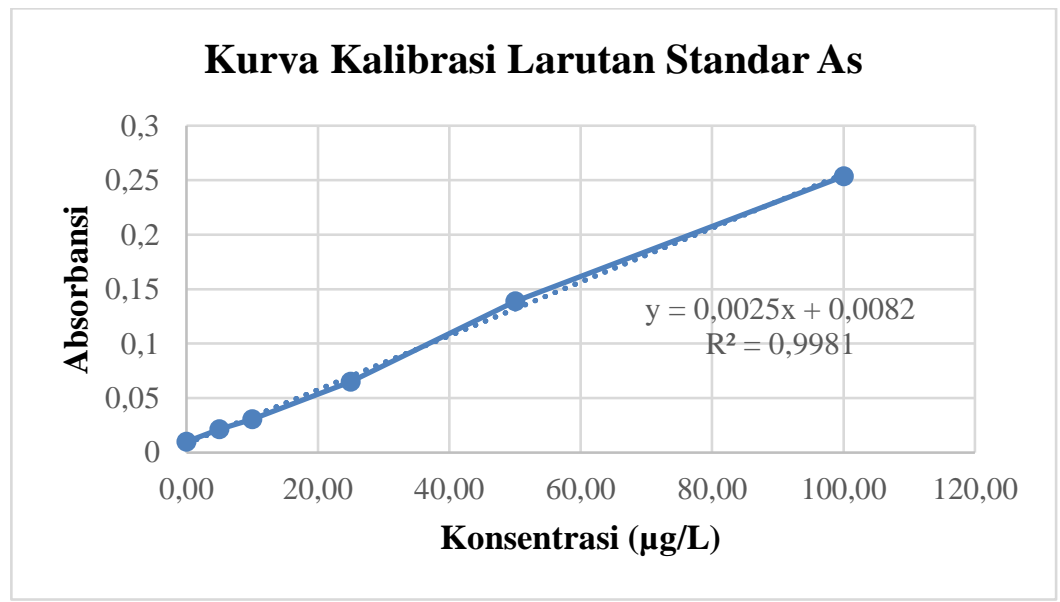

\section{Gambar 4. Kurva Kalibrasi Hasil Uji Linearitas Logam Arsen}

Berdasarkan gambar kurva kalibrasi di atas diperoleh harga koefisien korelasi $(r)$ sebesar 0,9981 . Hal ini menunjukkan bahwa alat AAS yang digunakan mempunyai respons yang sangat baik karena memiliki koefisien regresi > 0,990 (Suyono, 2015; Sari, 2019).

\subsection{Hasil Analisis Pengukuran Logam Arsen}

Tabel 3. Hasil Analisis Data Efisiensi Penurunan Logam Arsen Setelah Proses Adsorpsi pada Beberapa Variasi Massa Adsorben alami

\begin{tabular}{|c|c|c|c|c|c|}
\hline No & Nama sampel & $\begin{array}{c}\text { Konsentrasi } \\
\text { Arsen } \\
\text { (mg/L) }\end{array}$ & $\begin{array}{c}\text { Rata-rata } \\
\text { konsentrasi } \\
\text { Arsen } \\
\text { (mg/L) }\end{array}$ & $\begin{array}{c}\% \\
\text { Efisiensi }\end{array}$ & $\begin{array}{c}\text { Rata-Rata \% } \\
\text { Efisiensi }\end{array}$ \\
\hline \multirow[t]{2}{*}{1} & \multirow[b]{2}{*}{ Kitosan- Ampas Kopi 0,6 gr } & 1,77 & \multirow[b]{2}{*}{1,71} & 69,14 & \multirow[b]{2}{*}{70,25} \\
\hline & & 1,64 & & 71,37 & \\
\hline \multirow[t]{2}{*}{2} & \multirow[b]{2}{*}{ Kitosan-Ampas Kopi 0,8 gr } & 1,44 & \multirow[b]{2}{*}{1,47} & 74,95 & \multirow[b]{2}{*}{74,31} \\
\hline & & 1,51 & & 73,67 & \\
\hline \multirow[t]{2}{*}{3} & \multirow[b]{2}{*}{ Kitosan-Ampas Kopi 1,0 gr } & 1,18 & \multirow[b]{2}{*}{1,12} & 79,40 & \multirow[b]{2}{*}{80,57} \\
\hline & & 1,05 & & 81,73 & \\
\hline \multirow[t]{2}{*}{4} & \multirow[b]{2}{*}{ Kitosan-Ampas Kopi 1,2 gr } & 0,87 & \multirow[b]{2}{*}{0,94} & 84,77 & \multirow[b]{2}{*}{83,71} \\
\hline & & 1,00 & & 82,64 & \\
\hline \multirow[t]{2}{*}{5} & \multirow{2}{*}{ Kitosan-Ampas Kopi 1,4 gr } & 0,81 & \multirow{2}{*}{0,79} & 85,91 & \multirow{2}{*}{86,18} \\
\hline & & 0,78 & & 86,44 & \\
\hline
\end{tabular}

Berdasarkan data rata-rata hasil analisa konsentrasi logam arsen pada penggunaan adsorben alami kitosan yang dikombinasikan karbon aktif ampas kopi maka seluruh variasi massa adsorben alami kitosan dan karbon aktif ampas kopi belum memenuhi baku mutu yang telah ditetapkan Peraturan Menteri Lingkungan Hidup Nomor P12 Tahun 2020 pada Lampiran III tentang baku mutu air limbah pada kolam penampung air di fasilitas penyimpanan limbah B3 berupa tempat tumpukan limbah (waste pile) dan waste impoundment yaitu sebesar $0,1 \mathrm{mg} / \mathrm{L}$ 
(Menteri LH, 2020). Dalam hal ini perlu dilakukan penelitian lanjutan mengenai peningkatan massa karbon aktif dari ampas kopi yang digunakan sehingga dapat menurunkan konsentrasi logam arsen dalam air limbah sampai memenuhi baku mutu yang ditetapkan.

Berdasarkan Tabel 3 dapat dirumuskan grafik penurunan konsentrasi arsen pada air limbah sebelum dan sesudah adsorbsi yang disajikan pada Gambar 5 sebagai berikut:

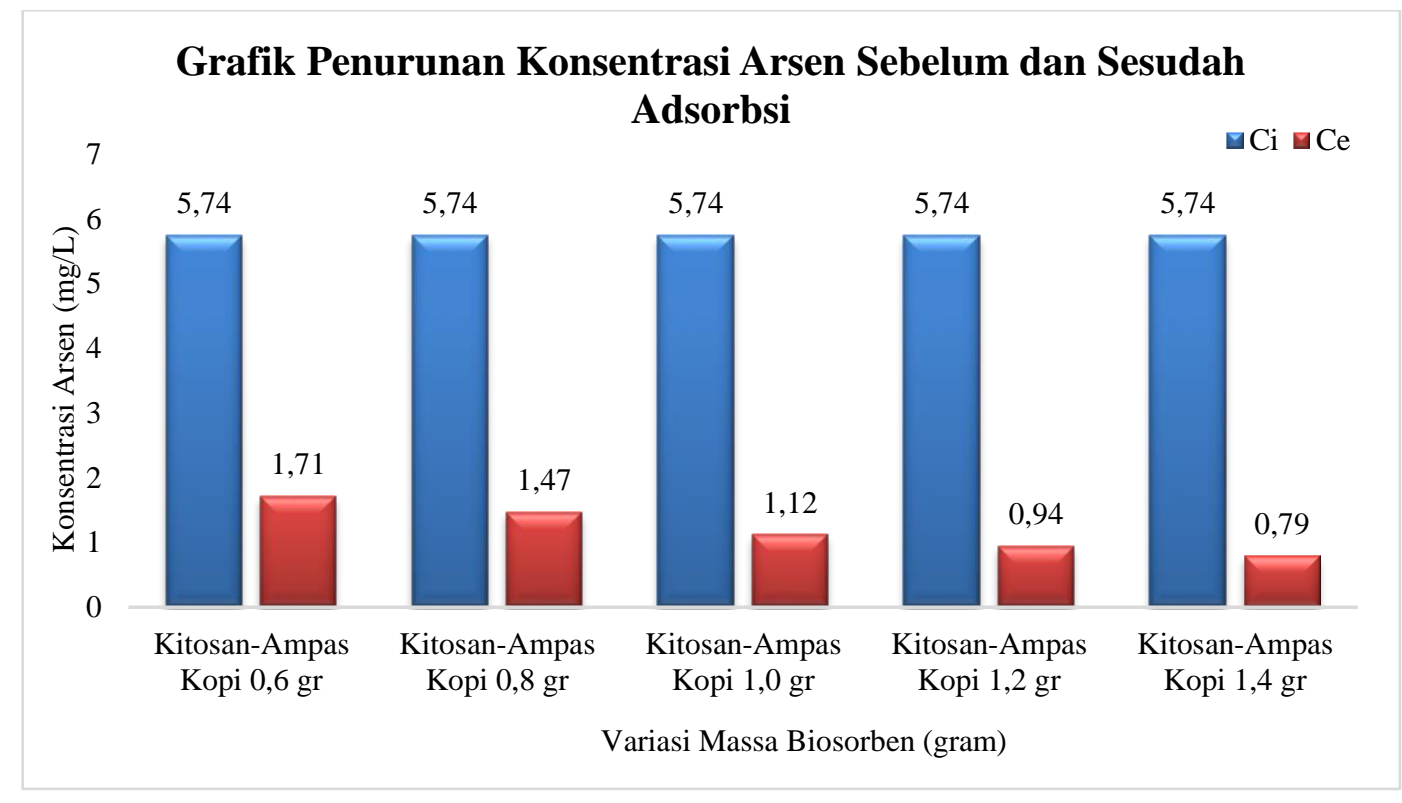

\section{Gambar 5. Grafik Penurunan Konsentrasi Arsen pada Air Limbah Sebelum dan Sesudah Adsorbsi}

Grafik tersebut menunjukkan bahwa konsentrasi logam arsen sebelum adsorpsi sebesar 5,74 $\mathrm{mg} / \mathrm{L}$, kemudian mengalami penurunan untuk setiap variasi massa adsorben alami yang digunakan. Berdasarkan grafik pada gambar 5 tersebut dapat disimpulkan bahwa semakin banyak massa karbon aktif ampas kopi yang dikombinasikan dengan kitosan yang digunakan dalam proses adsorpsi maka kecil konsentrasi arsen yang dihasilkan setelah proses adsorpsi atau semakin besar penurunan konsentrasi arsen yang dihasilkan (Dai, et al., 2016). Hal ini dikarenakan kemampuan adsorpsi adsorben alami akan meningkat seiring dengan peningkatan dosisnya, yang dikaitkan dengan aksesibilitas peningkatan situs penyerapan aktif untuk proses penyerapan logam arsen pada air limbah (Naga Babu, et al., 2018). Dalam hal ini adanya karbon aktif dari ampas kopi pada adsorben alami menyebabkan peningkatan komponen senyawa organik berupa $\mathrm{n}$ - asam heksadekanoat dan $\mathrm{n}$-asam oktadekanoat yang dapat meningkatkan kapasitas penyerapan kitosan (Pujol, et al., 2013).

Dari data pada Gambar 5, maka dapat dirumuskan efisiensi penurunan logam arsen pada berbagai variasi massa adsorben alami sebagai berikut: 
Efektivitas Kombinasi Kitosan dan Ampas Kopi sebagai Adsorben Alami dalam Menurunkan Konsentrasi Arsen Pada Limbah Cair PT PXI

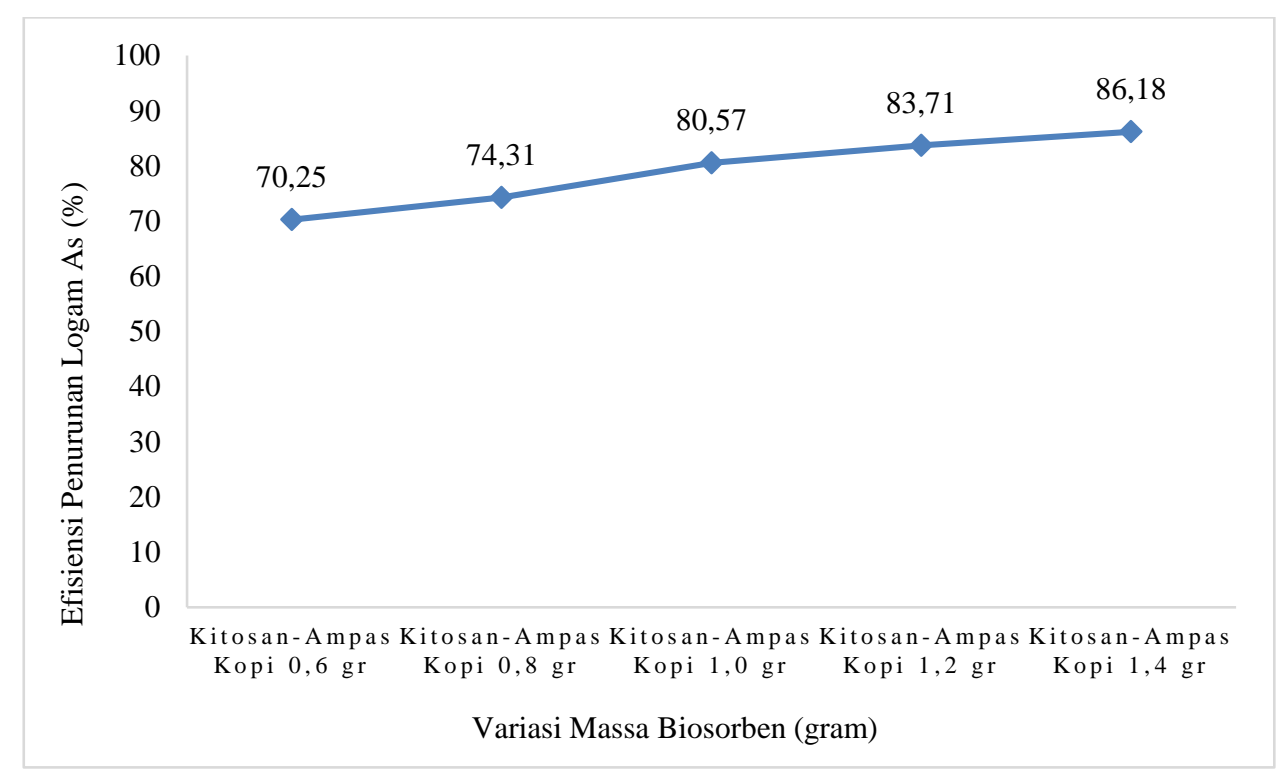

\section{Gambar 6. Grafik Efisiensi Penurunan Konsentrasi Arsen pada Air Limbah pada berbagai variasi massa adsorben alami}

Gambar 6 di atas menunjukkan bahwa efisiensi penurunan logam arsen pada penggunaan adsorben alami kitosan dan karbon aktif ampas kopi 0,6 gram sebesar 70,25\%, pada adsorben alami kitosan dan karbon aktif ampas kopi 0,8 gram sebesar 74,31\%, pada adsorben alami kitosan dan karbon aktif ampas kopi 1,0 gram sebesar 80,57\%, pada adsorben alami kitosan dan karbon aktif ampas kopi 1,2 gram sebesar 83,71\% dan pada adsorben alami kitosan dan karbon aktif ampas kopi 1,4 gram sebesar $86,18 \%$. Hal ini menunjukkan bahwa semakin tinggi dosis karbon aktif ampas kopi yang dikombinasikan dengan kitosan akan semakin meningkatkan efisiensi penyerapan logam arsen dalam air limbah. Sesuai dengan pernyataan pada hasil penelitian sebelumnya yang menyatakan bahwa kuantitas adsorben alami adalah faktor kunci penting untuk proses biosorpsi (Sahu et al, 2021). Hal ini juga didukung keberadaan situs aktif yang dibuktikan dari hasil karakterisasi SEM yang menunjukkan permukaan adsorben alami kitosan-karbon aktif ampas kopi terdiri dari beberapa situs pori dengan tepian sangat kasar dan bergelombang. Hal ini menunjukkan ketersediaan permukaan aktif yang signifikan untuk proses adsorpsi dari kontaminan logam berat arsen di dalam air limbah (Rajput et al 2016; Altowayti et al, 2019). Hasil karakterisasi EDX adsorben alami kitosan dan ampas kopi 1,4 gram menunjukkan adanya 74,30\% karbon; 18,29\% Oksigen; 0,88\% Natrium; 0,34\% Magnesium: 2,99\% timah, 0,51\% zirkonium; 0,53\% tembaga; 0,46\% zink; $0,46 \%$ klorin; $0,42 \%$ kalium; $0,34 \%$ fosfor; $0,27 \%$ kalsium; $0,15 \%$ silikon dan $0,06 \%$ aluminium.

\subsection{Hasil Karakterisasi Adsorben kitosan dan karbon aktif ampas kopi}

Hasil karakterisasi gugus fungsi adsorben alami kitosan-karbon aktif ampas kopi menggunakan FT-IR disajikan pada Gambar 7 sebagai berikut: 


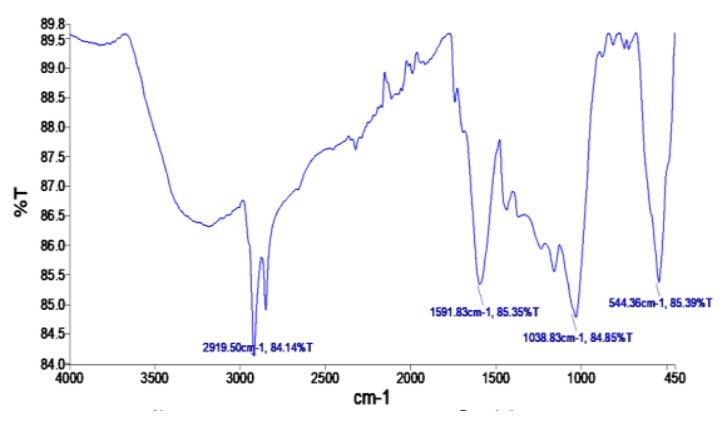

a)

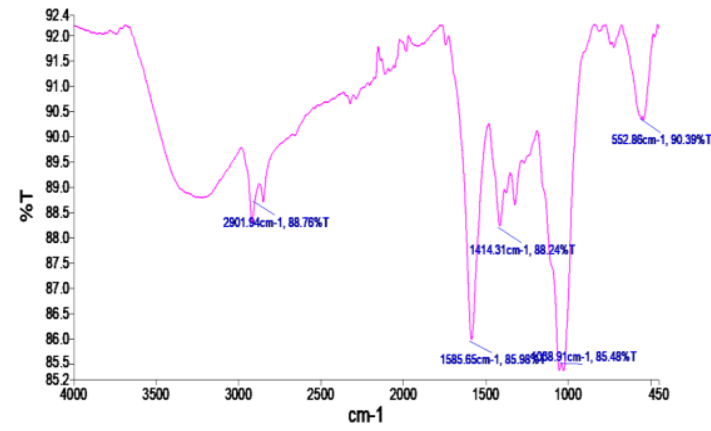

b)

\section{Gambar 8. Hasil Spektrum FT-IR dari Adsorben alami a)Karbon aktif ampas kopi dan b) Kitosan-Karbon Aktif Ampas Kopi}

Berdasarkan gambar 8 tersebut di atas dapat ditentukan beberapa gugus fungsi yang terdapat dalam adsorben alami kombinasi kitosan-karbon aktif ampas kopi berdasarkan referensi sesuai Tabel 4 sebagai berikut:

Tabel 4. Analisis Data FT-IR karbon aktif ampas kopi dan Kitosan-Karbon Aktif Ampas Kopi

\begin{tabular}{|c|c|c|c|c|}
\hline \multirow[t]{2}{*}{ Puncak } & \multicolumn{3}{|c|}{ Panjang gelombang $\left(\mathrm{cm}^{-1}\right)$} & \multirow{2}{*}{$\begin{array}{l}\text { Gugus } \\
\text { Fungsi }\end{array}$} \\
\hline & $\begin{array}{l}\text { Karbon aktif ampas } \\
\text { kopi }\end{array}$ & $\begin{array}{l}\text { Kombinasi kitosan- } \\
\text { karbon aktif ampas kopi }\end{array}$ & $\begin{array}{l}\text { Referensi } \\
\text { (Mohamed et al 2017) }\end{array}$ & \\
\hline 1 & 2919,50 & 2901,94 & 3000-2850 (alkana stretch) & $\mathrm{C}-\mathrm{H}$ \\
\hline 2 & 1591,83 & 1585,65 & $\begin{array}{l}\text { 1640-1550 (primary, } \\
\text { secondary amines and } \\
\text { amides: bend) }\end{array}$ & $\mathrm{N}-\mathrm{H}$ \\
\hline 3 & - & 1414,31 & 1550 - 1350 (nitro: R-NO2) & $\mathrm{N}=\mathrm{O}$ \\
\hline \multirow[t]{2}{*}{4} & \multirow[t]{2}{*}{1038,83} & \multirow[t]{2}{*}{1038,91} & $\begin{array}{l}\text { 1300-1000 (alcohol, ethers, } \\
\text { esters, carboxylic acids, } \\
\text { anhydrides) }\end{array}$ & $\mathrm{C}-\mathrm{O}$ \\
\hline & & & $1350-1000$ (amines) & $\mathrm{C}-\mathrm{N}$ \\
\hline 5 & 544,46 & 552,86 & 785-540 (chloride) & $\mathrm{C}-\mathrm{Cl}$ \\
\hline
\end{tabular}

Berdasarkan tabel 4 diatas menunjukkan bahwa hasil analisis spektrum FT-IR pada karbon aktif ampas kopi terdapat beberapa puncak serapan antara lain menunjukkan adanya gugus fungsi $\mathrm{C}-\mathrm{H}$ (sebagai alkana), $\mathrm{N}-\mathrm{H}$ ( kemungkinan sebagai amina sekunder/ primer dan amida), C-O (kemungkinan sebagai alkohol/ eter/ ester/ asam karboksilat/anhidrida), C-N (amina) dan $\mathrm{C}-\mathrm{Cl}$ (klorida). Sedangkan hasil analisis spektrum FT-IR pada kitosan - karbon aktif ampas kopi terdapat beberapa puncak serapan antara lain menunjukkan adanya gugus fungsi $\mathrm{C}-\mathrm{H}$ (sebagai alkana), $\mathrm{N}-\mathrm{H}$ (kemungkinan sebagai amina sekunder/ primer dan amida), $\mathrm{N}=\mathrm{O}$ (nitro), C-O (kemungkinan sebagai alkohol/ eter/ ester/ asam karboksilat/anhidrida), C-N (amina) dan C-Cl (klorida) (Mohamed et al, 2017). Berdasarkan hasil analisa FT-IR tersebut menunjukkan adanya penambahan gugus fungsi $\mathrm{N}=\mathrm{O}$ pada adsorben alami kitosan - karbon aktif ampas kopi dibandingkan dengan karbon aktif ampas kopi. Hal ini menunjukkan bahwa interaksi yang terjadi antara karbon aktif ampas kopi dan kitosan adalah interaksi fisik (Sari,2019) dan interaksi kimia berupa reaksi oksidasi nitrogen yang menyebabkan terbentuknya gugus nitro $\left(\mathrm{NO}_{2}\right)$ pada adsorben alami kitosan - karbon aktif ampas kopi. 


\section{KESIMPULAN}

Berdasarkan hasil penelitian yang diperoleh dapat disimpulkan bahwa penggunaan adsorben alami dapat menghasilkan efektivitas penurunan logam arsen tertinggi sebesar $86,18 \%$ dengan konsentrasi akhir sebesar 0,79 mg/L pada penggunaan kombinasi kitosan dengan penambahan karbon aktif ampas kopi sebesar 1,4 gram. Namun hasil tersebut belum memenuhi baku mutu logam arsen yang telah ditetapkan Peraturan Menteri Lingkungan Hidup Nomor P12 Tahun 2020 pada Lampiran III tentang baku mutu air limbah pada kolam penampung air di fasilitas penyimpanan limbah B3 berupa tempat tumpukan limbah (waste pile) dan waste impoundment yaitu sebesar $0,1 \mathrm{mg} / \mathrm{L}$. Sehingga perlu dilakukan penelitian lebih lanjut dengan meningkatkan massa karbon aktif ampas kopinya agar terjadi peningkatan efisiensi penurunan logam arsen dan dapat memenuhi baku mutu yang telah ditetapkan.

\section{UCAPAN TERIMA KASIH}

Peneliti mengucapkan terima kasih kepada DIPA Direktorat Jenderal Pendidikan Tinggi, Kementerian Pendidikan, Kebudayaan, Riset, dan Teknologi Tahun Anggaran 2021 atas dukungan dana penelitian yang telah diberikan dan Universitas Pelita Bangsa yang telah memfasilitasi pengajuan penelitian dasar dan pembinaan/kapasitas pada kontrak penelitian Nomor 036/KP/7.NA/UPB/VII/2021 sehingga penelitian dapat dilaksanakan dengan baik.

\section{DAFTAR RUJUKAN}

Altowayti, W.A.H., Algaifi,H.A., Bakar, S.A., \& Shahir, S. (2019). The adsorptive removal of As (III) using biomass of arsenic resistant Bacillus thuringiensis strain WS3: Characteristics and modelling studies. Ecotoxicology and Environmental Safety, 172, 176-185

American Public Health Association (APHA). (2017). Electrothermal Atomic Absorption Spectrometric Method. Part. 3113 B. Washington, DC.

Ayunda, S., Nurmala,L. \& Ramadhana. (2019). Adsorpsi Logam Cd²+ Menggunakan Adsorben alami berbasis komposit Film Kitosan - Limbah Cangkang Kopi, J. Reaksi (Journal Sci. Technol.), 17(2),13-21.

BSN. 2005. Air dan air limbah - Bagian 54 : Cara uji kadar arsen (As) dengan Spektrofotometer Serapan Atom (SSA) secara tungku karbon. SNI 06-6989.54-2005

Cherdchoo, W., Nithettham, S., \& Charoenpanich, J. (2019). Removal of Cr(VI) from synthetic wastewater by adsorption onto coffee ground and mixed waste tea, Chemosphere, 221, 758-767, doi: 10.1016/j.chemosphere.2019.01.100.

Dai, Y., Zhang,D., \& Zhang, K. (2016). Nitrobenzene-adsorption capacity of $\mathrm{NaOH}$-modified spent coffee ground from aqueous solution. Journal of the Taiwan Institute of Chemical Engineers 2016, 1-7.

Hazimah., \& Triwuri, Nurlinda Ayu. (2018). Analisis Kandungan Arsenik (As) dan Sianida (CN) Depot Air Minum Isi Ulang Di Kota Batam. Jurnal Rekayasa Sistem Industri, 3(2), 130. 
Kim, M.S., Min, H.G., Koo, N., Park, J., Lee, S.H., Bak, G.I., \& Kim, J.G. (2014). The effectiveness of spent coffee grounds and its biochar on the amelioration of heavy metals-contaminated water and soil using chemical and biological assessments, Journal Environmental Management., 146, 124-130. doi: 10.1016/j.jenvman.2014.07.001.

Lessa, E. F., Nunes,M.L., \& Fajardo, A. R. (2018). Chitosan/ waste coffee-grounds composite: An efficient and eco-friendly adsorbent for removal of pharmaceutical contaminants from water, Carbohydrate Polymer, 189, 257-266. doi: 10.1016/j.carbpol.2018.02.018.

Menteri Lingkungan Hidup. (2020). Peraturan Menteri Lingkungan Hidup Nomor P12 Tahun 2020 pada Lampiran III tentang baku mutu air limbah pada kolam penampung air di fasilitas penyimpanan limbah B3 berupa tempat tumpukan limbah (waste pile) dan waste impoundment, 5.

Mohamed, M.A., Jaafar,J., Ismail, A.F., Othman, M.H.D. \& Rahman, M.A. (2017). Chapter 1 Fourier Transform Infrared (FTIR) Spectroscopy. Membrane Characterization, 3-29.

Naga Babu, A., Reddy D. S., Kumar G. S., Ravindhranath K., \& G. V. Krishna Mohan. (2018). "Removal of lead and fluoride from contaminated water using exhausted coffee grounds based bio-sorbent," Journal Environmental Management, 218, 602-612. doi: 10.1016/j.jenvman.2018.04.091.

Pujol, D., Liua, C., Gominhoc, J., Olivella, M.A., Fiol, N., Villaescusaa, I. \& Pereira, H. (2013). The chemical composition of exhausted coffee waste. Ind Crops Prod. 50, 423-429.

Park, M.H S., Jeong, S., Lee, G., Park, H., \& J. Y. Kim. (2019). Removal of aqueous-phase $\mathrm{Pb}(\mathrm{II}), \mathrm{Cd}(\mathrm{II}), \mathrm{As}(\mathrm{III})$, and $\mathrm{As}(\mathrm{V})$ by nanoscale zero-valent iron supported on exhausted coffee grounds, Waste Management, 92, 49-58. doi:10.1016/j.wasman.2019.05.017

PT PXI, Safety Data Sheet Laboratorium, Material Safety Data Sheet, vol. 4 , no. 2. pp. 2012, [Online]. Available: https://us.vwr.com/assetsvc/asset/en_US/id/16490607/contents.

Rajput, Shalini, Pittman Jr., Charles U., Mohan, \& Dinesh. (2016). Magnetic magnetite $\left(\mathrm{Fe}_{3} \mathrm{O}_{4}\right)$ nanoparticle synthesis and applications for lead $\left(\mathrm{Pb}^{2+}\right)$ and chromium $\left(\mathrm{Cr}^{6+}\right)$ removal from water. J. Colloid Interface Sci. 468, 334-346.

Sahu, N., Saigh,J. \& Koduru, J.R. (2021). Removal of arsenic from aqueous solution by novel iron and iron-zirconium modified activated carbon derived from chemical carbonization of Tectona grandis sawdust: Isotherm, kinetic, thermodynamic and breakthrough curve modelling. Environmental Research . 200, 111431. 
Efektivitas Kombinasi Kitosan dan Ampas Kopi sebagai Adsorben Alami dalam Menurunkan Konsentrasi Arsen Pada Limbah Cair PT PXI

Sari, F.P. (2019). Pembuatan dan Karakterisasi Kitosan-Karbon Aktif dari Ampas Kopi Sebagai Adsorben Untuk Menurunkan Kadar Logam Kadmium dan Nikel, Tesis Pascasarjana Ilmu Kimia FMIPA Universitas Sumatera Utara.

Suyono. (2015). Analisis regresi untuk penelitian. Yogyakarta:Deepublish. 